\title{
New Pair of 2-Amino-naphthoxazoles Derived from $\beta$-Lapachone: Synthesis, Spectral Evaluation and Crystal Structure
}

\author{
Leonardo A. Silva, ${ }^{(0 *, a}$ Emanoel Hottes, ${ }^{a}$ Ari M. da Silva, ${ }^{b}$ Luan M. S. Freire,${ }^{a}$ \\ Guilherme P. Guedes ${ }^{\circledR c}$ and Aurélio B. B. Ferreira ${ }^{\dagger, a}$
}

${ }^{a}$ Instituto de Química, Universidade Federal Rural do Rio de Janeiro, 23890-000 Seropédica-RJ, Brazil

${ }^{b}$ Instituto de Pesquisas em Produtos Naturais, Universidade Federal do Rio de Janeiro, 21944-970 Rio de Janeiro-RJ, Brazil

'Instituto de Química, Universidade Federal Fluminense, 24020-141 Niterói-RJ, Brazil

This work describes a novel synthetic route for obtaining 2-amino-naphthoxazoles derived from $\beta$-lapachone, which consists of a condensation reaction between $\beta$-lapachone and thiourea in a basic medium. This synthetic approach can be seen as a potential route for obtaining 2-amino-oxazoles from quinones. The obtained amino-naphthoxazoles were characterized by spectroscopic techniques and the crystal structure of one of them was resolved by X-ray diffraction. The experimental results were compared to that obtained through density functional theory (DFT) calculations, revealing high correlation coefficients.

Keywords: $\beta$-lapachone, naphthoxazoles, synthesis, crystal structure

\section{Introduction}

The oxazolic and the imidazolic derivatives of $\beta$-lapachone (1) have been studied for decades due to their potential to combat the etiological agents Trypanosoma cruzi, ${ }^{1-4}$ which causes Chagas disease, and Mycobacterium tuberculosis, ${ }^{5,6}$ which causes tuberculosis. In recent research by our group, ${ }^{7}$ we pointed out that the inductive effects of the substituents bonded to the imidazolic nucleus contributes to the antitrypanosomal activity of these compounds. Due to the similarities between imidazoles and oxazoles, it is reasonable to believe that the

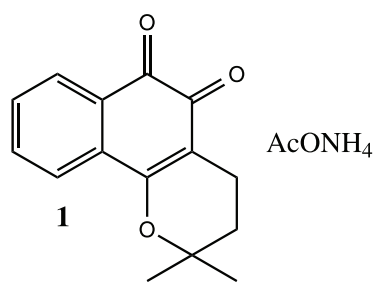



$$
\mathrm{R}=\mathrm{H}
$$

same feature could improve the oxazole activity against T. cruzi. However, in the methods found in the literature, ${ }^{8}$ the oxazoles derived from $\beta$-lapachone are obtained in most cases as byproducts of imidazole syntheses, which involve the condensation of $\beta$-lapachone with ammonia and an aldehyde. Since these methods are almost always limited to aromatic aldehydes, where the group bonded to carbonyl becomes the substituent at position 2 of the heterocycle, the variety of the substituents at this position is restricted (Scheme 1,i). ${ }^{8.9}$ One of the few exceptions reported is in the condensation with paraformaldehyde, in which the product has a hydrogen at position 2 (Scheme $1, i i) .{ }^{10}$

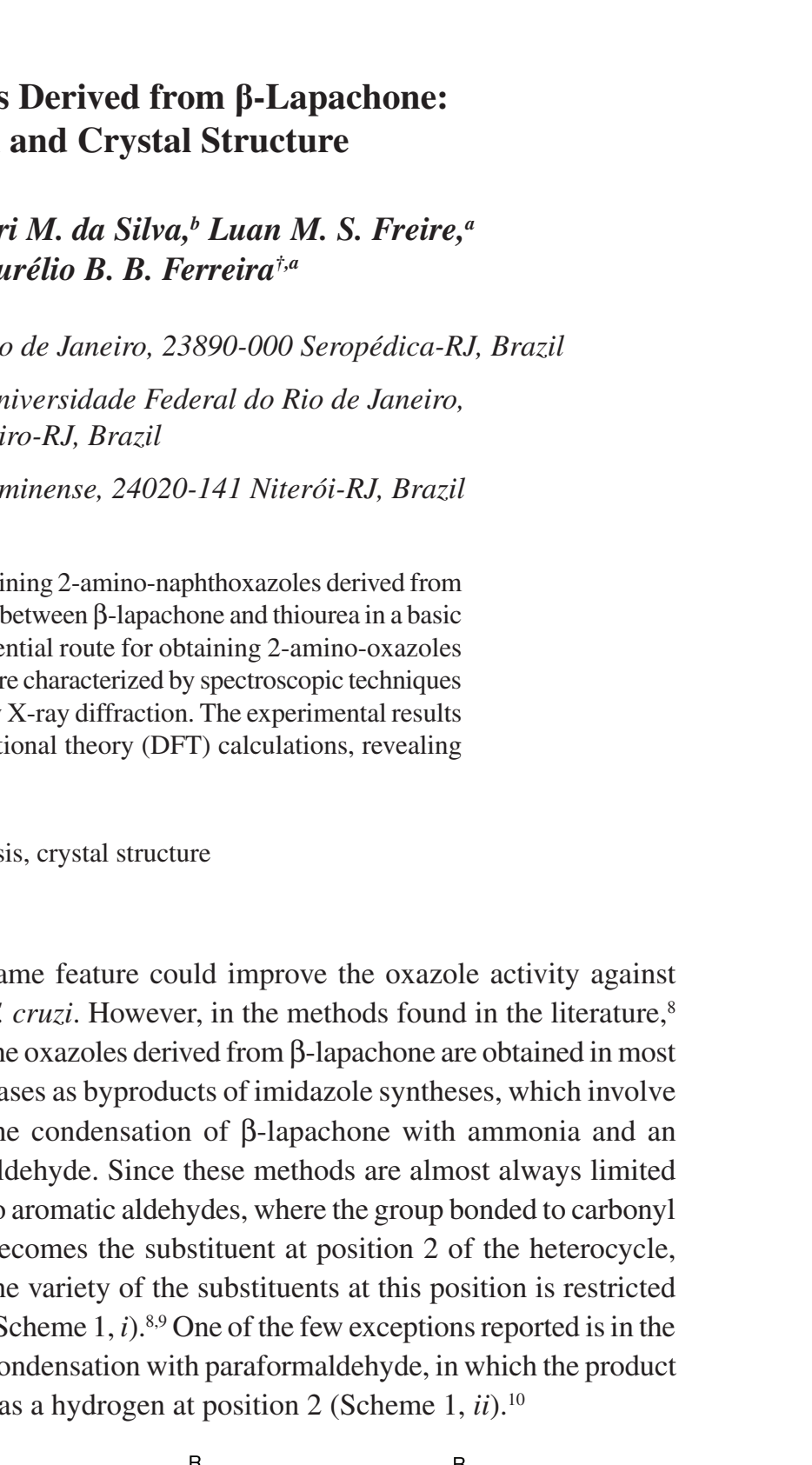

Scheme 1. Syntheses of naphthoimidazoles and naphthoxazoles derived from $\beta$-lapachone (imidazoles: $\mathrm{X}=\mathrm{NH}$, $\mathrm{Y}=\mathrm{N}$; oxazoles: $\mathrm{X}=\mathrm{O}$, $\mathrm{Y}=\mathrm{N}$ ); method (i) (adapted from reference 8) and method (ii) (adapted from reference 10).

\footnotetext{
*e-mail: leonardoaraujo@ufrrj.br
}

$\dagger$ In memoriam. 
The amino group $\left(-\mathrm{NH}_{2}\right)$ is one of the substituents capable of increasing the electronic density of aromatic rings, as it is an electron donor by resonance, as can be seen in the comparison between nuclear magnetic resonance (NMR) spectra of arylamines and aromatic compounds with other substituents. ${ }^{11}$ Furthermore, this group is a potential precursor of others, like amides and nitro. ${ }^{12}$

In this work we describe the synthesis of a pair of 2-amino-naphthoxazoles isomers ( $\mathbf{2}$ and $\mathbf{3}$ ) derived from $\beta$-lapachone using a novel synthetic method developed by us (Scheme 2), and their characterization through vibrational spectroscopy (infrared and Raman), high resolution mass spectrometry (HRMS), ${ }^{1} \mathrm{H}$ and ${ }^{13} \mathrm{C}$ nuclear magnetic resonance (NMR) (uni and bidimensional), UV-Visible absorption and emission spectra and single crystal X-ray diffraction, as well as a comparison between the experimental results and theoretical calculations.

\section{Experimental}

\section{General}

Reagents $\left(\mathrm{K}_{2} \mathrm{CO}_{3}\right.$ and thiourea) and solvents hexane, methanol, ethyl acetate and dimethyl sulfoxide (SigmaAldrich, St. Louis, USA) were used without any pretreatment. Melting points were obtained using a Reichert micro hot stage. Column chromatography was performed using silica 220-440 mesh particle size, $60 \AA$ (Merck, Darmstadt, Germany).

The HRMS were obtained using a Bruker MicroTOF II electrospray ionization instrument. The main fragments were described as a relation between the atomic mass units and the charge $(\mathrm{m} / \mathrm{z})$ and the relative abundance in percentage of the base peak intensity. NMR spectra were obtained in a solution of deuterated dimethyl sulfoxide (DMSO- $d_{6}$ ) in a Bruker Advance III (500 MHz) or Bruker Advance II (400 MHz) spectrometer, using tetramethylsilane (TMS) as the internal standard. The Fourier transform infrared with attenuated total reflectance (FTIR-ATR) and the Fourier transform Raman (FT-Raman) spectra of solid samples were obtained, respectively, by Vertex 70 and in MultiRam

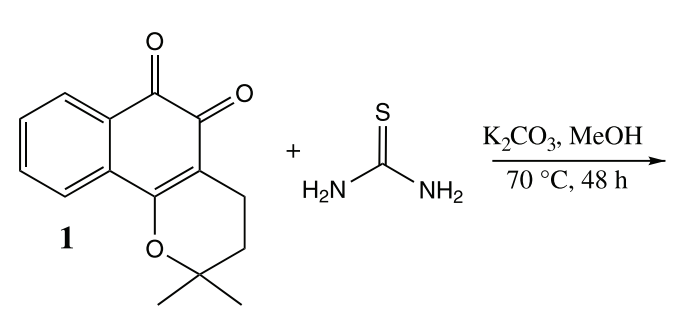

spectrometers (both from Bruker), with resolution of $4 \mathrm{~cm}^{-1}$ and 32 scans. UV-Visible absorption and emission spectra were recorded with a Jasco J-815 spectrofluorometer equipped with a Jasco PFD-425S15F thermostat system with $0.1{ }^{\circ} \mathrm{C}$ accuracy. The UV-Vis absorption was measured in a $1.0 \mathrm{~cm}$ quartz cell in the range of 200-700 $\mathrm{nm}$ using a $3 \mathrm{~mL}$ solution of compound 2 in methanol $\left(1.948 \times 10^{-5} \mathrm{M}\right)$ at $293 \mathrm{~K}$. The molar absorption coefficients $(\varepsilon)$ were measured by applying the Beer-Lambert law $(\varepsilon=\mathrm{A} / \mathrm{c} \lambda$, where A represents absorbance, $\lambda$ is the wavelength and $\mathrm{c}$ is the speed of light) to the maximum of each band and the values for band gap energy (E) were calculated through the Planck-Einstein equation $(\mathrm{E}=\mathrm{hc} / \lambda)$, where $\mathrm{h}$ and $\mathrm{c}$ are constants and $\lambda$ is the cutoff wavelength.

\section{Single-crystal X-ray diffraction}

X-ray diffraction data were collected with a Bruker D8-Venture diffractometer using Mo K $\alpha$ radiation $(\lambda=0.71073 \AA)$ at room temperature $(298 \mathrm{~K})$. Data collection and cell refinement were performed with a Bruker Instrument Service and APEX3, respectively. ${ }^{13}$ Data reduction was carried out using SAINT. ${ }^{14}$ The absorption correction using equivalent reflections was performed with the SADABS program. ${ }^{15}$ The structure solution and fullmatrix least-squares refinement based on $F^{2}$ were performed with the SHELXS ${ }^{16}$ and SHELXL ${ }^{17}$ programs, respectively, implemented in OLEX2. ${ }^{18}$ All atoms except hydrogen were refined anisotropically. The structures were drawn by the Mercury program. ${ }^{19}$

\section{Computational details}

All calculations were performed using the SPARTAN'14 software..$^{20}$ For the reaction mechanism study, the semiempirical method PM6 basis set was used and follow-up calculations were performed just considering the main product, compound $\mathbf{2}$. The acquisition of the theoretical vibrational spectra of compound $\mathbf{2}$ was performed in the gas phase using the density functional theory (DFT) with the Becke-3-Lee Yang Parr (B3LYP) method and standard

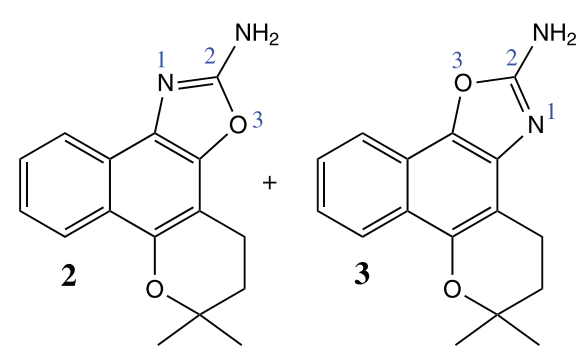

Scheme 2. Synthesis of naphthoxazoles $\mathbf{2}$ and $\mathbf{3}$ from $\beta$-lapachone. 
6-31G* basis set. ${ }^{21}$ The same method and the same set of bases were used to obtain the NMR spectra and the geometric parameters of the molecular structure (bond lengths, torsion and dihedral angles), but the equilibrium geometry was previously performed in dimethylsulfoxide (DMSO), which was the same solvent used in those experimental sections. After the structure optimization in DMSO, the NMR spectra and the geometric parameters were acquired in the gas phase.

\section{$\beta$-Lapachone synthesis}

$\beta$-Lapachone was obtained by lapachol isomerization with sulfuric acid and purification by recrystallization. ${ }^{22}$

Synthesis of 6,6-dimethyl-5,6-dihydro-4H-benzo[7,8] chromeno[6,5-d][1,3]oxazol-2-amine and 6,6-dimethyl-5,6dihydro-4H-benzo[7,8]chromeno[5,6-d][1,3]oxazol-2-amine

In three $10 \mathrm{~mL}$ reaction vials, the following amounts were added in each one: $80.7 \mathrm{mg}$ of $\beta$-lapachone, $76 \mathrm{mg}$ of thiourea and $4.5 \mathrm{~mL}$ of methanol. The mixtures were stirred at room temperature until solubilization. Then, in each vial, $23 \mathrm{mg}$ of $\mathrm{K}_{2} \mathrm{CO}_{3}$ were added. The vials were sealed and heated to $65^{\circ} \mathrm{C}$ for $48 \mathrm{~h}$ on a heating plate. The total amount of each of the substances used in the reaction were $242.1 \mathrm{mg}$ ( $1 \mathrm{mmol}$ ) of $\beta$-lapachone, $228 \mathrm{mg}$ ( $3 \mathrm{mmol}$ ) of thiourea, $69 \mathrm{mg}$ of $\mathrm{K}_{2} \mathrm{CO}_{3}(0.5 \mathrm{mmol})$ and $14.5 \mathrm{~mL}$ of methanol. After the reaction time, the three mixtures were joined, the solvent was removed by evaporation and the solid mixture was submitted to partition with ethyl acetate and water, to remove the potassium carbonate and the excess of thiourea. The products retained in the organic phase were separated by column chromatography using a 1:1 mixture of hexane and ethyl acetate.

\section{Crystallization of compound 2}

A solution containing $16 \mathrm{mg}$ of compound 2 in $1.5 \mathrm{~mL}$ of DMSO- $d_{6}$ (used for the NMR experiment) was left exposed to atmospheric air for 30 days, affording single crystals. These crystals were analyzed by FTIR-ATR, Raman and X-ray diffraction.

\section{Results and Discussion}

\section{Synthesis}

The synthesis reaction provided $237 \mathrm{mg}$ of compound $\mathbf{2}$, as a moss green solid (mp 205-208 ${ }^{\circ} \mathrm{C}$ ), and $16 \mathrm{mg}$ of compound $\mathbf{3}$ (oil). These products were characterized by HRMS, ${ }^{1} \mathrm{H}$ NMR and ${ }^{13} \mathrm{C}$ NMR. The overall reaction and the yields obtained from the syntheses of naphthoxazoles 2 and $\mathbf{3}$ are shown in Scheme 3.

Other methods for oxazole synthesis from $\beta$-lapachone also had greater selectivity for production of the compound with the nitrogen of the heterocycle at position 6 of the chromene system. ${ }^{8}$ Assuming that one of the oxazole formation steps is a nucleophilic attack from one of the thiourea nitrogens to one of the $\beta$-lapachone carbonyls, the higher yield of isomer $\mathbf{2}$ indicates that this attack occurs preferably at $\mathrm{C}(6)$. This regioselectivity of the nucleophilic attack also occurs in the synthesis of other 4-alcoxynaphthoquinone derivatives, in addition to $\beta$-lapachone, as in the synthesis of $\alpha$-diazocarbonyl compounds, ${ }^{23,24}$ oximes $^{25}$ and arylimines. ${ }^{26}$

The enthalpies of formation ( $\left.\Delta \mathrm{H}_{\text {form }}\right)$ of the final products and of the intermediates that are formed at the beginning were determined using the semi empirical method PM6. Despite the limitations of this semi-empirical method, these calculations corroborated the tendency to preferentially form compound 2 due to the lower energy values of its precursors compared to the precursors of compound $\mathbf{3}$ (see Supplementary Information (SI) section).

In the various tests carried out to improve the reaction yield, no products were formed in the absence of base (or with acidic media). Thiourea deprotonation, producing its conjugated base, seems to be a crucial point, due to its greater nucleophilicity.

With similar conditions (shown in Scheme 3), we also
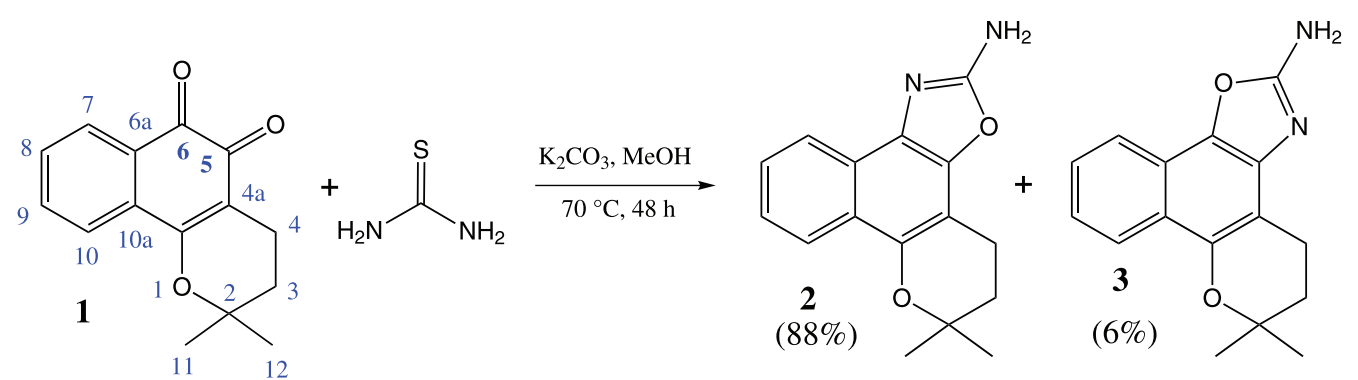

Scheme 3. Reaction between $\beta$-lapachone and thiourea, producing 2 (6,6-dimethyl-5,6-dihydro- $4 H$-benzo[7,8]chromeno[6,5- $d][1,3]$ oxazol-2-amine) and 3 (6,6-dimethyl-5,6-dihydro-4H-benzo[7,8]chromeno[5,6- $d][1,3]$ oxazol-2-amine). 
carried out the reaction with urea instead of thiourea, but the yields were much lower: $20 \%$ for isomer 2 and $4 \%$ for isomer 3 . A factor that may have contributed to this decrease was the lower $\mathrm{p} K_{\mathrm{a}}$ value of thiourea $\left(\mathrm{p} K_{\mathrm{a}}=21\right)$ compared to that of urea $\left(\mathrm{p} K_{\mathrm{a}}=27\right) .{ }^{27}$ This indicates that the reaction with thiourea should not pass through the formation of urea or the exchange of sulfur for oxygen, in one of the steps. Therefore, the oxygen that makes up the oxazolic nucleus comes from carbonyl oxygen of $\beta$-lapachone and the sulfur should be eliminated after the formation of the oxazolic system.

\section{Crystal structure of compound 2 and comparison with DFT calculations}

Compound $\mathbf{2}$ crystallizes in the triclinic $\mathrm{P} \overline{1}$ space group and its asymmetric unit is shown in Figure 1. A summary of the crystal structure, data collection and refinement parameters are given in Table 1. Selected bond lengths and angles are listed in Table 2.

Table 1. Summary of the crystal structure, data collection and refinement parameters for $\mathbf{2}$

\begin{tabular}{lc}
\hline Chemical formula & $\mathrm{C}_{16} \mathrm{H}_{16} \mathrm{~N}_{2} \mathrm{O}_{2}$ \\
Formula weight / $\left(\mathrm{g} \mathrm{mol}^{-1}\right)$ & 268.31 \\
Crystal system & triclinic \\
$a / \AA$ & $5.8593(13)$ \\
$b / \AA$ & $10.810(3)$ \\
$c / \AA$ & $11.415(3)$ \\
$\alpha /$ degree & $108.432(8)$ \\
$\beta /$ degree & $90.466(7)$ \\
$\gamma /$ degree & $98.891(7)$ \\
Unit cell volume / $\AA^{3}$ & $676.4(3)$ \\
Temperature / K & 298 \\
Space group & $\mathrm{P} \overline{1}$ \\
No. of formula units per unit cell $(Z)$ & 2 \\
Radiation type & $\mathrm{Mo} \mathrm{K \alpha}$ \\
Absorption coefficient $(\mu) / \mathrm{mm}^{-1}$ & 0.09 \\
No. of reflections measured & 11067 \\
No. of independent reflections & 2580 \\
$\mathrm{R}_{\text {int }}$ & 0.056 \\
$\mathrm{R}\left[\mathrm{F}^{2}>2 \sigma\left(\mathrm{F}^{2}\right)\right]$ & 0.058 \\
$w \mathrm{R}\left(\mathrm{F}^{2}\right)$ & 0.177 \\
Goodness of fit on $\mathrm{F}^{2}$ & 1.04 \\
Largest diff. peak and hole / $\left(\mathrm{e} \AA^{-3}\right)$ & 0.46 and -0.22 \\
$\mathrm{CCDC}$ ID & 2026764 \\
\hline
\end{tabular}

$a-c$ and $\alpha-\gamma$ : unit cell parameters; $\mathrm{R}_{\text {int }}$ : internal $\mathrm{R}$-value; $\mathrm{w}=1 /\left[\sigma^{2}\left(\mathrm{~F}_{\mathrm{o}}^{2}\right)+(0.0862 \mathrm{P})^{2}+0.3716 \mathrm{P}\right]$, where $\mathrm{P}=\left(\mathrm{F}_{\mathrm{o}}^{2}+2 \mathrm{~F}_{\mathrm{c}}^{2}\right) / 3 ; \mathrm{F}^{2}$ : squared structure factor; CCDC ID: Cambridge Crystallographic Data Centre identification.

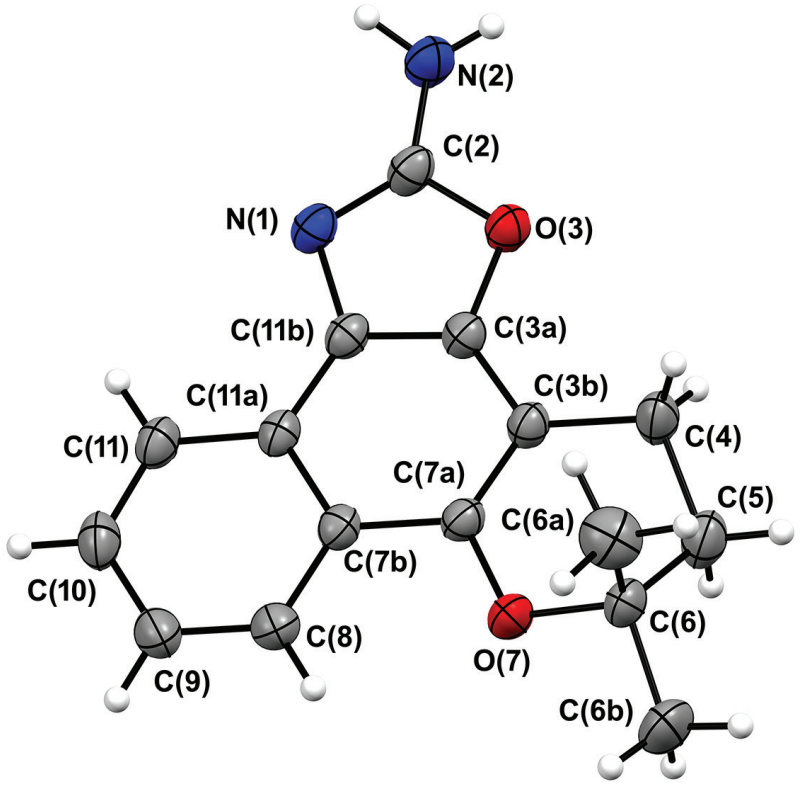

Figure 1. Thermal ellipsoids of the asymmetric unit of compound $\mathbf{2}$ drawn at $40 \%$ probability level. Color code: gray $=$ carbon, white $=$ hydrogen, blue $=$ nitrogen, and red $=$ oxygen.

Table 2. Comparison between the experimental and theoretical values for the bond lengths, bond angles and torsion angles of the oxazolic ring in $\mathbf{2}$

\begin{tabular}{|c|c|c|}
\hline Bond length & $\operatorname{Exp} / \AA$ & B3LYP / Å \\
\hline $\mathrm{C}(3 \mathrm{a})-\mathrm{O}(3)$ & $1.384(3)$ & 1.404 \\
\hline $\mathrm{O}(3)-\mathrm{C}(2)$ & $1.368(3)$ & 1.375 \\
\hline $\mathrm{N}(2)-\mathrm{C}(2)$ & $1.352(3)$ & 1.348 \\
\hline $\mathrm{N}(1)-\mathrm{C}(2)$ & $1.293(3)$ & 1.308 \\
\hline $\mathrm{N}(1)-\mathrm{C}(11 \mathrm{~b})$ & $1.408(2)$ & 1.399 \\
\hline $\mathrm{C}(11 \mathrm{~b})-\mathrm{C}(3 \mathrm{a})$ & $1.364(3)$ & 1.380 \\
\hline $\mathrm{R}^{2}$ & \multicolumn{2}{|c|}{0.909} \\
\hline Bond angle & Exp / degree & B3LYP / degree \\
\hline $\mathrm{C}(3 \mathrm{a})-\mathrm{O}(3)-\mathrm{C}(2)$ & $103.3(2)$ & 103.24 \\
\hline $\mathrm{O}(3)-\mathrm{C}(2)-\mathrm{N}(2)$ & $115.7(2)$ & 115.56 \\
\hline $\mathrm{N}(1)-\mathrm{C}(2)-\mathrm{N}(2)$ & $128.2(2)$ & 128.11 \\
\hline $\mathrm{O}(3)-\mathrm{C}(2)-\mathrm{N}(1)$ & 116.1(2) & 116.24 \\
\hline $\mathrm{C}(2)-\mathrm{N}(1)-\mathrm{C}(11 \mathrm{~b})$ & 103.2(2) & 103.35 \\
\hline $\mathrm{N}(1)-\mathrm{C}(11 \mathrm{~b})-\mathrm{C}(3 \mathrm{a})$ & $109.5(2)$ & 109.63 \\
\hline $\mathrm{C}(11 \mathrm{~b})-\mathrm{C}(3 \mathrm{a})-\mathrm{O}(3)$ & $107.9(2)$ & 107.53 \\
\hline$\underline{\mathrm{R}^{2}}$ & \multicolumn{2}{|c|}{0.999} \\
\hline Torsion angle & Exp / degree & B3LYP / degree \\
\hline $\mathrm{C}(3 \mathrm{a})-\mathrm{O}(3)-\mathrm{C}(2)-\mathrm{N}(2)$ & $-179.2(2)$ & -176.82 \\
\hline $\mathrm{C}(3 \mathrm{a})-\mathrm{O}(3)-\mathrm{C}(2)-\mathrm{N}(1)$ & $-1.3(3)$ & 0.17 \\
\hline $\mathrm{O}(3)-\mathrm{C}(2)-\mathrm{N}(1)-\mathrm{C}(11 \mathrm{~b})$ & $1.2(3)$ & -0.41 \\
\hline $\mathrm{C}(2)-\mathrm{N}(1)-\mathrm{C}(11 \mathrm{~b})-\mathrm{C}(3 \mathrm{a})$ & $-0.6(3)$ & 0.49 \\
\hline $\mathrm{N}(1)-\mathrm{C}(11 \mathrm{~b})-\mathrm{C}(3 \mathrm{a})-\mathrm{O}(3)$ & $-0.1(3)$ & -0.41 \\
\hline $\mathrm{C}(11 \mathrm{~b})-\mathrm{C}(3 \mathrm{a})-\mathrm{O}(3)-\mathrm{C}(2)$ & $0.8(3)$ & 0.16 \\
\hline $\mathrm{N}(2)-\mathrm{C}(2)-\mathrm{N}(1)-\mathrm{C}(11 \mathrm{~b})$ & $178.8(2)$ & 176.14 \\
\hline$\underline{\mathrm{R}^{2}}$ & \multicolumn{2}{|c|}{0.999} \\
\hline
\end{tabular}

Exp: experimental; B3LYP: Becke-3-Lee Yang Parr; $\mathrm{R}^{2}$ : correlation coefficient. 
The asymmetric unit is comprised of one molecule of 6,6-dimethyl-5,6-dihydro- $4 H$-benzo[7,8]chromeno $[6,5-d][1,3]$ oxazol-2-amine (2). The crystal structure revealed that the condensation between the $\beta$-lapachone precursor and thiourea leads to the oxazole moiety in $\mathbf{2}$, as also seen by ${ }^{1} \mathrm{H}$ NMR spectroscopy. Bond lengths for $\mathbf{2}$ are consistent with those previously reported ${ }^{6,28,29}$ for this class of compounds.

In order to go beyond in the structural study of this compound, the experimental parameters (bond lengths and angles) were compared to those simulated by DFT calculations, and the results are gathered in Table 2. The calculated values are in good agreement with the experimental ones, as can be seen through the correlation coefficients $\left(\mathrm{R}^{2}\right)$, which are greater than 0.9 .

The crystal packing of $\mathbf{2}$ is stabilized by the hydrogen bond involving the amino group and oxazolic nitrogen atom, with the following geometrical parameters: $\mathrm{N} 2-\mathrm{H} 2 \mathrm{a}=0.88(3) \AA, \mathrm{H} 2 \mathrm{a} \cdots \mathrm{N} 1^{\mathrm{i}}=2.09(3) \AA$, $\mathrm{N} 2 \cdots \mathrm{N} 1^{\mathrm{i}}=2.970(3) \AA$ and $\angle \mathrm{N} 2-\mathrm{H} 2 \mathrm{a} \cdots \mathrm{N} 1^{\mathrm{i}}=171(3)^{\circ}$, $\mathrm{i}=-\mathrm{x}-1,-\mathrm{y},-\mathrm{z}+1$. This intermolecular hydrogen bond leads to dimers of $\mathbf{2}$, which interacts each other by $\pi-\pi$ stacking between oxazole and naphthalenic rings, as depicted in Figure 2. The centroid-to-centroid distance is 3.48(2) ̊.

\section{Vibrational spectroscopy of compound 2}

The experimental and theoretical vibrational spectra (IR and Raman) were compatible and compound 2 belongs to the $\mathrm{C} 1$ dot group. Although deviations above $100 \mathrm{~cm}^{-1}$ were found in some bands in the theoretical spectra, the bands correlated to the vibrational modes showed the same patterns. These deviations can be attributed to the common interactions that occur in the solid state, in which the experimental spectra were performed, in contrast with the theoretical spectra, which were simulated in vacuum. Better correlations between the experimental and theoretical values were observed in the region from 1700 to $400 \mathrm{~cm}^{-1}$ than in the region from 3500 to $3200 \mathrm{~cm}^{-1}$, due to the stronger interactions (mainly hydrogen bonds) that occur in this last region. ${ }^{30,31}$ In the experimental FTIR spectrum (Figure S2, SI section), the band at $3419 \mathrm{~cm}^{-1}$ was attributed to $\mathrm{N}-\mathrm{H}$ stretching and the shoulders at 3402 and $3381 \mathrm{~cm}^{-1}$ should be associated with hydrogen bonds between the amino group of the molecules. ${ }^{32}$ In the theoretical IR spectrum (Figure S4, SI section, combined with the theoretical Raman spectrum) two bands were observed at 3672 and $3563 \mathrm{~cm}^{-1}$.

The influence of the hydrogen bond can also be observed in the Raman spectra, because there are no bands in this region in the experimental spectrum (Figure S3, SI section), but they are present in the theoretical one. This interaction in the solid state, which is the case of the experimental spectrum, should cause partial hardness of the $\mathrm{N}-\mathrm{H}$ bond, decreasing its tendency to polarization.

Since the $\mathrm{C}=\mathrm{C}$ and $\mathrm{C}=\mathrm{N}$ bonds of the chromene and oxazolic nuclei, respectively, are in the same plane, their stretches are coupled in an intense band at $1662 \mathrm{~cm}^{-1}$, followed by two lower bands of $\mathrm{C}=\mathrm{C}$ and $\mathrm{C}-\mathrm{N}$ of the same nuclei, in the same order. In the theoretical spectrum these stretches appears as three bands at 1716, 1680 and $1620 \mathrm{~cm}^{-1}$, respectively. In the experimental and theoretical Raman spectra, the coupled vibrational modes $\mathrm{C}=\mathrm{N} / \mathrm{C}=\mathrm{C}$ and $\mathrm{C}=\mathrm{C}$ were observed in the form of four bands: in the region from 1610 to $1531 \mathrm{~cm}^{-1}$ in the

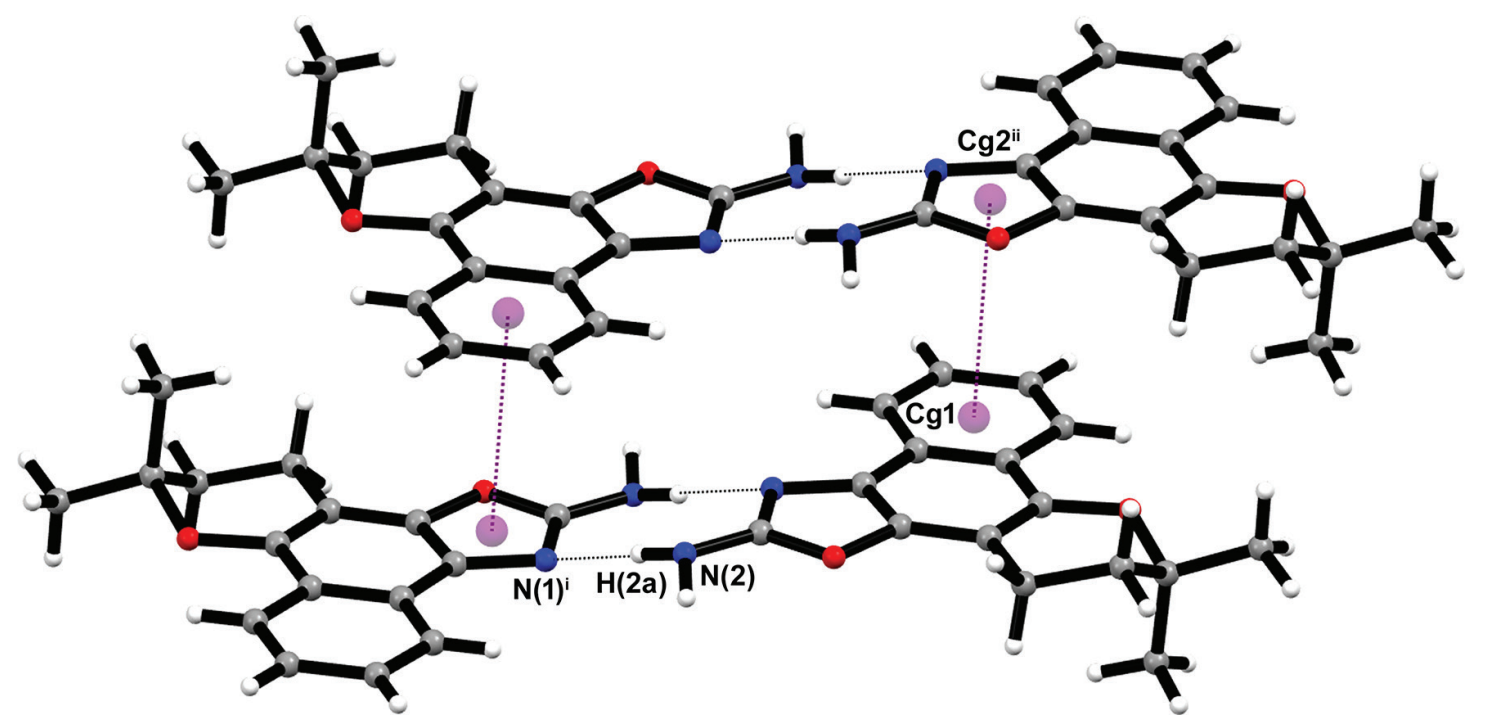

Figure 2. Details of the crystal packing of compound 2. The hydrogen bonds and $\pi$ - $\pi$ stacking between oxazole and naphthalenic rings are represented as black and purple dotted lines, respectively. Purple spheres represent the centroids. Symmetry operations: $i=-1-x,-y, 1-z$ and ii $=1+x, y, z$. 
experimental spectrum, and in the region from 1716 to $1579 \mathrm{~cm}^{-1}$, in the theoretical spectrum.

\section{Nuclear magnetic resonance}

Table 3 shows the values of chemical shifts determined in the nuclear magnetic resonance of ${ }^{1} \mathrm{H}$ (Figure S8, SI section) and ${ }^{13} \mathrm{C}$ (distortionless enhancement by polarization transfer (DEPTQ), Figure S9, SI section) of compound 2. Homonuclear (homonuclear correlation spectroscopy (HOMOCOSY), Figure S10, SI section) and heteronuclear (heteronuclear single quantum coherence (HSQC), Figure S11; heteronuclear multiple bond coherence (HMBC), Figure S12, SI section) were also used to assist in the structural elucidation of compounds $\mathbf{2}$ and $\mathbf{3}$. Good agreement was observed between the experimental and theoretical data (Figures S14 and S15, SI section) of compound $\mathbf{2}$, since the correlation coefficients $\left(\mathrm{R}^{2}\right)$ obtained were greater than 0.99 .

Table 3. Experimental and theoretical chemical shifts in ${ }^{1} \mathrm{H}$ and ${ }^{13} \mathrm{C}$ NMR spectra of compound 2

\begin{tabular}{lcccc}
\hline $\mathrm{C}, \mathrm{N}$ & $\begin{array}{c}{ }^{1} \mathrm{H} \mathrm{Exp} / \\
\mathrm{ppm}\end{array}$ & $\begin{array}{c}{ }^{1} \mathrm{H} \mathrm{B3LYP} / \\
\mathrm{ppm}\end{array}$ & $\begin{array}{c}{ }^{13} \mathrm{C} \text { Exp } / \\
\mathrm{ppm}\end{array}$ & $\begin{array}{c}{ }^{13} \mathrm{C} \mathrm{B3LYP} / \\
\mathrm{ppm}\end{array}$ \\
\hline 2 & - & - & 161.5 & 162.7 \\
$3 \mathrm{a}$ & - & - & 142.6 & 145.7 \\
$3 \mathrm{~b}$ & - & - & 102.0 & 102.2 \\
4 & $2.92(\mathrm{t}, J 6.62 \mathrm{~Hz})$ & 2.87 & 16.9 & 19.1 \\
5 & $1.91(\mathrm{t}, J 6.62 \mathrm{~Hz})$ & 1.85 & 31.0 & 31.8 \\
6 & - & - & 74.3 & 74.6 \\
$6 \mathrm{a} / 6 \mathrm{~b}$ & $1.39(\mathrm{~s})$ & 1.39 & 26.3 & 26.5 \\
$7 \mathrm{a}$ & - & - & 142.8 & 147.3 \\
$7 \mathrm{~b}$ & - & - & $122.9(2 \mathrm{C})$ & 123.9 \\
8 & $8.08(\mathrm{~d}, J 8.51 \mathrm{~Hz})$ & 8.17 & 121.9 & 123.8 \\
9 & $7.37(\mathrm{t}, J 7.57 \mathrm{~Hz})$ & 7.28 & 123.1 & 122.5 \\
10 & $7.47(\mathrm{t}, J 7.25 \mathrm{~Hz})$ & 7.36 & 125.3 & 125.1 \\
$11 \mathrm{a}$ & - & - & $122.9(2 \mathrm{C})$ & 125.5 \\
$11 \mathrm{~b}$ & - & - & 129.2 & 132.2 \\
11 & $8.01(\mathrm{~d}, J 7.88 \mathrm{~Hz})$ & 8.23 & 121.2 & 123.4 \\
$\mathrm{NH}_{2}(2)$ & $7.20(\mathrm{~s})$ & $\mathrm{a}$ & - & - \\
\hline $\mathrm{R}^{2}$ & & 0.998 & & \multicolumn{2}{c}{0.999} \\
\hline
\end{tabular}

${ }^{a}$ Not detected. Exp: experimental; B3LYP: Becke-3-Lee Yang Parr; $\mathrm{R}^{2}$ : correlation coefficient; s: singlet; d: doublet; t: triplet.

We assumed that the highest chemical shifts observed in the DEPTQ correspond to aromatic carbons bonded to heteroatoms, $\mathrm{C}(2), \mathrm{C}(3 \mathrm{a}), \mathrm{C}(7 \mathrm{a})$ and $\mathrm{C}(11 \mathrm{~b})$, which is in line with the observed values in the theoretical method. Thus, one of the key shifts is that of $\mathrm{C}(7 \mathrm{a})(\delta=143.4 \mathrm{ppm})$, since only it can couple with both aromatic and aliphatic hydrogen atoms with detectable intensities measured by the HMBC spectrum of correlations. These couplings occurred between $\mathrm{C}(7 \mathrm{a})$ and $\mathrm{H}_{2}(4)(\delta=2.92 \mathrm{ppm}, \mathrm{t})$, and between $\mathrm{C}(7 \mathrm{a})$ and $\mathrm{H}(8)(\delta=8.08 \mathrm{ppm}, \mathrm{d})$. The identification of the doublet of $\mathrm{H}(8)$ and of the triplet of $\mathrm{H}_{2}(4)$ allowed the identification of all other aromatic and aliphatic hydrogens, respectively, through the analysis of the correlations in HOMOCOSY.

By assigning the chemical shifts in the ${ }^{1} \mathrm{H}$ NMR spectra to each hydrogen, it was also possible to assign the chemical shifts of the carbons attached to them, through the correlations observed in the HSQC and confirmed by the HMBC. The singlet at $7.20 \mathrm{ppm}$ was the only one that did not correlate with carbons in the HSQC, and its integration corresponded to two hydrogen atoms. In the HMBC, the only carbon which couple with this singlet was the quaternary carbon, which has the highest chemical shift. In the theoretical spectrum, this shift corresponded to $\mathrm{C}(2)$, which is consistent with the fact that it is the carbon connected with the highest number of heteroatoms. Thus, the singlet at $7.20 \mathrm{ppm}$ in the ${ }^{1} \mathrm{H}$ NMR was assigned to the hydrogen atoms of $\mathrm{NH}_{2}(2)$.

There were only six chemical shifts of quaternary carbons detected in the aromatic region, although the molecule has seven such carbons. However, there was a more intense signal at $123.5 \mathrm{ppm}$, which showed correlations with all the hydrogens in the aromatic portion, indicating that this signal corresponds to the $\mathrm{C}(\mathrm{7b})$ and $\mathrm{C}(11 \mathrm{a})$ carbons, which also matches the theoretical spectrum.

\section{UV-Visible spectroscopy}

Three main bands were observed in the experimental UV-Vis absorption spectrum (Figure S16, SI section) of compound 2 in methanol, with maximums (and $\varepsilon$ in $\left.\mathrm{M}^{-1} \mathrm{~cm}^{-1}\right)$ at 210 (39 064), 249 (35 386) and 330 (7 623) $\mathrm{nm}$. The bands in the range of $200-280 \mathrm{~nm}$ were assigned to $\pi-\pi^{*}$ transition of naphthalenic system and the band at $330 \mathrm{~nm}$ was assigned to $\mathrm{n}-\pi^{*}$ transition, due to the presence of lone electron pairs in the oxazole and furan rings, and obviously in the amino group. A shoulder around $224 \mathrm{~nm}$ on the band at $210 \mathrm{~nm}$ and other two shoulders around 316 and $326 \mathrm{~nm}$ on the band at $330 \mathrm{~nm}$ indicated that the molecule has approximately six main absorptions.

Although the shape of the simulated UV-Vis spectrum (Figure S17, SI section) has only two bands, the calculations also indicated the occurrence of six main absorptions: 210, 217, 225, 238, 294, and $316 \mathrm{~nm}$. Since 
the calculations were performed in a vacuum, we expected that in the experimental spectrum the bands would have absorption maximums at longer wavelengths due to the effect of solvatochromism. The wavelengths, their band gaps, oscillator strengths and main electronic transitions calculated by DFT//B3LYP/6-31G* are listed in Table S1, SI section. These transitions were determined based on the contribution of each atomic orbital to the composition of the molecular orbitals.

Naphthoxazoles are recognized to be luminescent, ${ }^{33}$ and this is true for compound $\mathbf{2}$. Its irradiation at the maximum wavelength of the three absorption bands in methanol promotes the emission of light in the same region, $424 \mathrm{~nm}$, but the irradiation at $335 \mathrm{~nm}$ is the one that gives greater intensity to the light emitted (Figure S18, SI section). Thus, the electronic transition corresponding to this emission must be of the type $\pi^{*}$-n.

\section{Conclusions}

In this work, the condensation between $\beta$-lapachone and thiourea in a basic medium is shown to be an efficient method to obtain two new isomeric 2-amino-naphthoxazoles, with good yield for one of them. New studies with a larger amount of quinones and diketones should be performed to establish this method as a general method to obtain 2-amino-oxazoles, but until the present work there were no methods for the synthesis of this class of compounds by the condensation of an $\alpha$-dicarbonyl compound and thiourea. Furthermore, the use of computational DFT studies with the B3LYP method supported the characterization of the main product 2 .

\section{Supplementary Information}

Crystallographic data (excluding structure factors) for the structures in this work were deposited in the Cambridge Crystallographic Data Centre as supplementary publication number CCDC 2026764. Copies of the data can be obtained, free of charge, via https://www.ccdc.cam. ac.uk/structures/.

Supplementary information (FTIR, Raman, HRMS, and NMR spectra) is available free of charge at http://jbcs.sbq.org.br as PDF file.

\section{Acknowledgments}

This work was supported by the Brazilian research promotion agencies Coordenação de Aperfeiçoamento de Pessoal de Nível Superior (CAPES) and Conselho Nacional de Desenvolvimento Científico e Tecnológico (CNPq). G. P.
G. acknowledges financial support from Fundação Carlos Chagas de Amparo à Pesquisa do Estado do Rio de Janeiro (FAPERJ, project No. E-26/202.720/2018). The authors also thank the contributions of Dr Marcelo Hawrylak Herbst of PPGQ-UFRRJ, the analytical center of IPPN-UFRJ, for obtaining the mass spectra and LDRX-UFF for use of the laboratory facilities and data collection of compound 2. The authors of this work dedicate it to Prof Dr Aurélio B. B. Ferreira. The legacy left by Prof Aurélio is enormous, which includes the academic guidance of two of the authors of this work: Leonardo A. Silva and Ari M. da Silva. We will all be forever indebted to the professor for sharing a part of his great wisdom, which goes far beyond the field of chemistry, with us. The professor will always be a great inspiration for all of us.

\section{Author Contributions}

Leonardo A. Silva was responsible for conceptualization, methodology, validation, investigation, writing original draft, data curation, visualization; Emanoel Hottes for conceptualization, software, formal analysis, writing original draft; Ari M. da Silva for conceptualization, methodology; Luan M. S. Freire for validation; Guilherme P. Guedes for formal analysis, resources, writing-review and editing; Aurélio B. B. Ferreira for resources, writing: review and editing, supervision, project administration, funding acquisition.

\section{References}

1. de Moura, K. C. G.; Emery, F. S.; Neves-Pinto, C.; Pinto, M. C. F. R.; Dantas, A. P.; Salomão, K.; de Castro, S. L.; Pinto, A. V.; J. Braz. Chem. Soc. 2001, 12, 325.

2. Moura, K. C. G.; Salomão, K.; Menna-Barreto, R. F. S.; Emery, F. S.; Pinto, M. C. F. R.; Pinto, A. V.; de Castro, S. L.; Eur. J. Med. Chem. 2004, 39, 639.

3. Menna-Barreto, R. F. S.; Corrêa, J. R.; Cascabulho, C. M.; Fernandes, M. C.; Pinto, A. V.; Soares, M. J.; de Castro, S. L.; Parasitology 2009, 136, 499.

4. Bombaça, A. C. S.; Viana, P. G.; Santos, A. C. C.; Silva, T. L.; Rodrigues, A. B. M.; Guimarães, A. C. R.; Goulart, M. O. F.; da Silva Jr., E. N.; Menna-Barreto, R. F. S.; Free Radical Biol. Med. 2019, 130, 408.

5. Coelho, T. S.; Silva, R. S. F.; Pinto, A. V.; Pinto, M. C. F. R.; Scaini, C. J.; Moura, K. C. G.; Silva, P. A.; Tuberculosis 2010, 90, 293.

6. Moura, K. C. G.; Carneiro, P. F.; Pinto, M. C. F. R.; Silva, J. A.; Malta, V. R. S.; de Simone, C. A.; Dias, G. G.; Jardim, G. A. M.; Cantos, J.; Coelho, T. S.; Silva, P. E. A.; da Silva Jr., E. N.; Bioorg. Med. Chem. 2012, 20, 6482. 
7. da Silva, A. M.; Araújo-Silva, L.; Bombaça, A. C. S.; MennaBarreto, R. F. S.; Rodrigues-Santos, C. E.; Ferreira, A. B. B.; de Castro, S. L.; MedChemComm 2017, 8, 952.

8. Pinto, C. N.; Dantas, A. P.; Moura, K. C.; Emery, F. S.; Polequevitch, P. F.; Pinto, M. C.; de Castro, S. L.; Pinto, A. V.; Arzneim.-Forsch./Drug Res. 2000, 50, 1120.

9. de Castro, S. L.; Emery, F. S.; da Silva Jr., E. N.; Eur. J. Med. Chem. 2013, 69, 678.

10. da Silva, A. R.; da Silva, A. M.; Ferreira, A. B. B.; Bernardes, B. O.; da Costa, R. L.; J. Braz. Chem. Soc. 2008, 19, 1230.

11. Pavia, D. L.; Lampman, G. M.; Kriz, G. S.; Vyvyan, J. R.; Introduction to Spectroscopy, $4^{\text {th }}$ ed.; Cengage Learning: Belmont, CA, USA, 2008, ch. 5.

12. Phukan, K.; Devi, N.; J. Chem. Pharm. Res. 2011, 3, 1037.

13. APEX3, version 2016/1-0; Bruker AXS Inc., Madison, WI, USA, 2007.

14. SAINT, version 38-7A; Bruker AXS Inc., Madison, WI, USA, 2007.

15. SADABS, version 2014/5; Bruker AXS Inc., Madison, WI, USA, 2001.

16. Sheldrick, G. M.; Acta Crystallogr., Sect. A: Found. Adv. 2008 , $64,112$.

17. Sheldrick, G. M.; Acta Crystallogr., Sect. C: Struct. Chem. 2015, 71, 3 .

18. Dolomanov, O. V.; Bourhis, L. J.; Gildea, R. J.; Howard, J. A. K.; Puschmann, H.; J. Appl. Crystallogr. 2009, 42, 339.

19. Macrae, C. F.; Edgington, P. R.; McCabe, P.; Pidcock, E.; Shields, G. P.; Taylor, R.; Towler, M.; van de Streek, J.; J. Appl. Crystallogr. 2006, 39, 453.

20. Shao, Y.; Molnar, L. F.; Jung, Y.; Kussmann, J.; Ochsenfeld, C.; Brown, S. T.; Gilbert, A. T. B.; Slipchenko, L. V.; Levchenko, S. V.; O’Neill, D. P.; DiStasio Jr., R. A.; Lochan, R. C.; Wang, T.; Beran, G. J. O.; Besley, N. A.; Herbert, J. M.; Lin, C. Y.; van Voorhis, T.; Chien, S. H.; Sodt, A.; Steele, R. P.; Rassolov, V. A.; Maslen, P. E.; Korambath, P. P.; Adamson, R. D.; Austin, B.; Baker, J.; Byrd, E. F. C.; Dachsel, H.; Doerksen, R. J.; Dreuw, A.; Dunietz, B. D.; Dutoi, A. D.; Furlani, T. R.; Gwaltney, S. R.; Heyden, A.; Hirata, S.; Hsu, C-P.; Kedziora, G.; Khalliulin, R. Z.; Klunzinger, P.; Lee, A. M.; Lee, M. S.; Liang, W. Z.; Lotan, I.; Nair, N.; Peters, B.; Proynov, E. I.; Pieniazek, P. A.; Rhee, Y. M.; Ritchie, J.; Rosta, E.; Sherrill, C. D.; Simmonett, A. C.;
Subotnik, J. E.; Woodcock III, H. L.; Zhang, W.; Bell, A. T.; Chakraborty, A. K.; Chipman, D. M.; Keil, F. J.; Warshel, A.; Hehre, W. J.; Schaefer, H. F.; Kong, J.; Krylov, A. I.; Gill, P. M. W.; Head-Gordon, M.; Phys. Chem. Chem. Phys. 2006, 8, 3172; SPARTAN'14 Tutorial and User's Guide; Wavefunction Inc., Irvine, CA, USA, 2014.

21. Rodríguez-Becerra, J.; Olea-Azar, C.; Zapata-Torres, G.; Mendizabal, F.; Gonzáles, M.; Cerecetto, H.; J. Braz. Chem. Soc. 2010, 21, 1937.

22. Schaffner-Sabba, K.; Schmidt-Ruppin, K. H.; Wehrli, W.; Schuerch, A. R.; Wasley, J. W. F.; J. Med. Chem. 1984, 27, 990.

23. Ferreira, V. F.; Jorqueira, A.; Leal, K. Z.; Pimentel, H. R. X.; Seidl, P. R.; Silva, M. N.; Souza, M. C. B. V.; Pinto, A. V.; Wardell, J. L.; Wardell, S. M. S. V.; Magn. Reson. Chem. 2006, $44,481$.

24. Carvalho, C. E. M.; Ferreira, V. F.; Pinto, A. V.; Pinto, M. C. F. R.; Harrison, W.; Dyes Pigm. 2002, 52, 209.

25. Santos, V. L. A.; Moraes, M. O.; Pessoa, C. O.; Costa, M. P.; Gonsalves, A. A.; Araújo, C. R. M.; J. Chem. Pharm. Res. 2016, $8,202$.

26. Chenna, P. H.; Benedetti-Doctorovich, V.; Baggio, R. F.; Garland, M. T.; Burton, G.; J. Med. Chem. 2001, 44, 2486.

27. Gómez, D. E.; Fabbrizzi, L.; Licchelli, M.; Monzani, E.; Org. Biomol. Chem. 2005, 3, 1495.

28. Vinay, S. K.; Saminaparwin, G. S.; Arun, L. P.; J. Mol. Struct. 2016, 1114, 181.

29. Li, D.; Yang, D.; Wang, L.; Liu, X.; Wang, K.; Wang, J.; Wang, P.; Liu, Y.; Zhu, H.; Wang, R.; Chem. - Eur. J. 2017, 23, 6974.

30. Davis, F. T.; Brewster, M. E.; J. Forensic Sci. 1988, 33, 549.

31. Silverstein, R. M.; Webster, F. X.; Kiemle, D. J.; Spectrometric Identification of Organic Compounds, $7^{\text {th }}$ ed.; Wiley: New York, USA, 2005.

32. Kolev, T. M.; Velcheva, E. A.; Stamboliyska, B. A.; Spiteller, M.; Int. J. Quantum Chem. 2005, 102, 1069.

33. Carvalho, C. E. M.; Silva, A. S.; Brinn, I. M.; Pinto, A. V.; Pinto, M. C. F. R.; Lin, S.; Moore, T. A.; Gustc, D.; Maeder, M.; Phys. Chem. Chem. Phys. 2002, 4, 3383.

Submitted: October 14, 2020

Published online: January 6, 2021 